\title{
Participatory scenario development for integrated assessment of nutrient flows in a Catalan river catchment
}

\author{
F. Caille ${ }^{1}$, J. L. Riera ${ }^{2}$, B. Rodríguez-Labajos ${ }^{1}$, H. Middelkoop ${ }^{3}$, and A. Rosell-Melée ${ }^{1,4}$ \\ ${ }^{1}$ Inst. of Environmental Science and Technology (ICTA), Autonomous Univ. of Barcelona (UAB), Bellaterra 08193, Spain \\ ${ }^{2}$ Department of Ecology, University of Barcelona (UB), Diagonal 645, Barcelona 08028, Spain \\ ${ }^{3}$ Department of Physical Geography, Utrecht University (UU), P.O. Box 80.115, 3508 TC Utrecht, The Netherlands \\ ${ }^{4}$ Institució Catalana de Recerca i Estudis Avançats, Pg. Lluís Companys 23, 08010 Barcelona, Catalonia
}

Received: : 7 May 2007 - Published in Hydrol. Earth Syst. Sci. Discuss.: 31 May 2007

Revised: 1 October 2007 - Accepted: 5 November 2007 - Published: 28 November 2007

\begin{abstract}
Rivers in developed regions are under significant stress due to nutrient enrichment generated mainly by human activities. Excess nitrogen and phosphorus emissions are the product of complex dynamic systems influenced by various factors such as demographic, socio-economic and technological development. Using a Catalan river catchment, La Tordera (North-East of Spain), as a case study of an integrated and interdisciplinary environmental assessment of nutrient flows, we present and discuss the development of narrative socio-economic scenarios through a participatory process for the sustainable management of the anthropogenic sources of nutrients, nitrogen and phosphorus. In this context, scenarios are an appropriate tool to assist nutrient emissions modelling, and to assess impacts, possible pathways for socio-economic development and associated uncertainties. Evaluated against the 1993-2003 baseline period, scenarios target the 2030 horizon, i.e. through the implementation process of the Water Framework Directive (Directive 2000/60/EC). After a critical examination of the methodology used in the participatory development of socio-economic scenarios, we present four possible futures (or perspectives) for the Catalan river catchment conceived by stakeholders invited to a workshop. Keys to the success of such a participatory process were trust, which enhanced openness, and disagreements, which fostered the group's creativity for scenario development. The translation of narrative socio-economic scenarios into meaningful nutrient emission scenarios is also discussed. By integrating findings of natural sciences and socio-economic analysis, we aim to assist decision makers and stakeholders in evaluating optimal management strategies for the anthropogenic sources of nitrogen and phosphorus.
\end{abstract}

Correspondence to: F. Caille

(frederique.caille@uab.es)

\section{Introduction}

The interactions among social agents and the environment are ultimately responsible for the evolution of nutrient loads (i.e. nitrogen and phosphorus; Cole et al., 1993; Vitousek et al., 1997; Bennet et al., 2001). Nutrient management in river basins requires not only the identification and quantification of nutrient sources but also an understanding of all relevant natural and social processes and their interactions; in short, nutrient management calls for integrated environmental assessments (IEA) (Bailey et al., 1996). The message of interdisciplinarity and policy relevance conveyed by IEA implies a broad and strategic look at the issue that contrasts sharply with the more traditional top-down view of policy making (Bailey, 1996; Hisschemöller et al., 2001; Rotmans and Dowlatabadi, 1997; Toth and Hizsnyik, 1998). By allowing a synoptic perspective on the causes and effects involved (Rotmans et al., 1996), IEA facilitates an understanding of the interactions and feedbacks between the natural and the social systems involved in the dynamics of river nutrient loads. This understanding is crucial to manage effectively the various sources of nutrient emissions.

Traditionally, river basin management has been reactive, focussing on the reduction of point nutrient sources mostly through the construction of waste water treatment plants. However, it is increasingly being recognised that we also should attempt to foresee problems and take a proactive and preventive approach. Proactive management is also better suited to accommodate societal action in environmental policy development and governance (Berry and Rondinelli, 1998). This can be accomplished through a variety of approaches, including participation and policy evaluation as part of an integrated assessment modelling. Models are widely used to explore options for catchment management and to analyse the evolution of specific state

Published by Copernicus Publications on behalf of the European Geosciences Union. 
variables (e.g. nutrient concentrations and loads) in relation to a driving force of interest (e.g. land use or climate change) (Hofmann et al., 2005; Brown Gaddis et al., 2007). This is done by simulating scenarios. However, models (and modellers) are by themselves inadequate for defining goals and specifying scenarios, a task that is often entrusted to a panel of experts. Yet this is an area that can greatly benefit from the involvement of stakeholders, as the European Union Water Framework Directive (WFD), adopted in 2000, recognises. With the objective of achieving the effective implementation of effective water management for the protection of all European natural water bodies, and to improve decision-making processes, the WFD encourages public participation. At its most basic, participation at the local level allows the collection of practical information for scientific assessments and policy-making, but it also serves to better adapt measures to local conditions, to include people concerned in the design process and eventually to raise public acceptance (WFD, 2002b). The WFD distinguishes between providing information, consultation and public participation (or active involvement). All these different and gradually more relevant forms of participation contribute to the participatory policy analysis which underlies Participatory Integrated Assessment (PIA) (Ridder and Pahl-Wolst, 2005), a set of methods and techniques that aim at supporting policy development by designing and facilitating active involvement of social agents, and eventually fostering debate and argumentation in an environmental management process (Hisschemöller et al., 2001). The development and use of scenarios is one of the most appropriate approaches to contribute to this aim as it is an efficient way to gather information from expert judgements.

Scenarios are useful instruments to think about the future and to build storylines about how the future might develop (Nakicenovic et al., 2000). In the definition of the Intergovernmental Panel on Climate Change (IPCC), which is commonly adopted in environmental applications, scenarios are described as alternative futures that are neither predictions nor forecasts, but contrasting images of how the future might unfold (Parry and Carter, 1998; Rotmans et al., 2000). Scenarios are widely used to explore uncertain futures, to assess possible pathways for socio-economic development, to identify management strategies and to present alternative views or images of the future with the aim to provide insights into the present (Berkhout et al., 2002; Burt and van der Heijden, 2003; Ledoux et al., 2005). Thus, by synthesising and communicating complex and extensive information to decision makers and the public, scenarios make decision-making more robust and help identify strategies for pre-empting undesirable future developments (Carter et al., 2001; Van der Heijden, 1996).

Scenarios are not only a way to see the future. They also enable to highlight uncertainties, which will always characterise the future. Thus, rather than allowing accurate prediction, they enable "learning" by showing how the future may deviate from planned events (Van der Heijden, 1996).
Although over short periods of time many important structures, processes and attitudes might remain unchanged, we are aware that over longer periods of time, social and economic relationships change, and that institutional and technological innovations modify prevailing trends. This is the domain of scenarios. In this context, the process of scenario construction can be seen as a sequence of "what if?" questions. This approach encourages participants to evaluate possible causal chains and to reflect on the series of consequences of a range of possible futures, generating scenarios that are self-consistent and comparable (Kahn and Wiener, 1967; Berkhout et al., 2002). The goal is to develop a number of diverging stories, commonly called "narratives" or "storylines", by focusing on the nature and impact of the driving forces that are identified as being both uncertain and heavily influencing. Thus, scenarios at the catchment scale are recognised as essential tools for planning and communication (Raskin et al., 1998), and also for representing efficiently environmental changes caused by a specific socio-economic context. When used together with a catchment model, scenarios can be run to assess the impact of relevant socioeconomic indicators on the environment.

The participatory development of scenarios applied to nutrient emissions problems at the catchment scale in the Mediterranean region is quite novel; we are not aware of any precedent published in the scientific literature. Yet it is of interest in the context of the current efforts to develop programmes of measures for river basins as required by the WFD and the European Statement for a New Culture of Water (NCW), adopted in Madrid in 2005 by a group of European scientists. The NCW considers the WFD as an essential and necessary contribution in the pursuit of the defence of human and citizen rights in the context of democratic governance based on transparence, participation and citizen control to reach social and environmental sustainability (Arrojo, 2006).

This paper is a contribution to the elaboration of a common toolkit for scenario development, which may allow sharing and comparing experiences. We present and discuss a participatory process to develop local socio-economic scenarios relevant to the evolution of nutrient flows in a Catalan river catchment (La Tordera, NE Spain) for the 2030 horizon. This was done for research purposes, without immediate policy implications, as part of an integrated assessment which includes a modelling effort to identify and quantify nutrient sources and emissions between 1993 and 2003, and an analysis of the social context relevant to catchment management, including the identification of stakeholders and the analysis of their interactions. The process presented here for the development of scenarios will serve as a basis for the elaboration of quantitative nutrient emissions scenarios in a separate paper. Our specific goals are: (1) to critically examine the methodology used in the participatory development of socio-economic scenarios, (2) to present and discuss the results of a scenario-development workshop for 
La Tordera catchment with selected stakeholders, and (3) to discuss the translation of narrative socio-economic scenarios into meaningful nutrient emission scenarios. Finally, we discuss the utility of scenarios for the sustainable management of nutrient sources in La Tordera.

\section{Study area}

The Tordera basin $\left(877 \mathrm{~km}^{2}\right)$ is located in Catalonia (NE Spain), about $60 \mathrm{~km}$ north-east of Barcelona (Fig. 1). La Tordera stream originates in the Montseny massif (maximum altitude, $1712 \mathrm{~m}$ a.s.l.), and runs for about $60 \mathrm{~km}$ along the valley formed by this massif and the littoral mountain range of Montnegre before ending in a delta between two important coastal tourist towns, Malgrat de Mar and Blanes. The bedrock in the catchment is mainly composed of plutonic and metamorphic rocks, with sandy quaternary deposits forming wide terraces and a significant fluvial aquifer in the lower section of the river. The climate is sub-humid Mediterranean (mean annual precipitation: $850 \mathrm{~mm} / \mathrm{yr}$ over the last $10 \mathrm{yrs}$ ); accordingly, river flow is highly variable both within and among years (median discharge at Fogars, $10 \mathrm{~km}$ upstream the mouth of La Tordera, was $0.95 \mathrm{~m}^{3} / \mathrm{s}$ from 1994 to 2003 , with a range from 0 to $170 \mathrm{~m}^{3} / \mathrm{s}$ ). The catchment spreads over 25 municipalities from three counties (La Selva, El Vallès Oriental and El Maresme), and includes sections of two Natural Parks: Montseny and Montnegre. The main land uses are agricultural (16\%), mostly on the low elevation north-eastern part of the catchment, urban and industrial (7\%), mostly along the main valley, and forests and grassland (77\%), covering most of the mountainous terrain (Fig. 1).

The population of La Tordera catchment has changed over the last thirty years. Indeed, the population of the catchment increased from 70000 inhabitants in 1975 to 88000 in 1995 and 122500 in 2005. This trend reflects changes in human activities in La Tordera catchment, which have substantially increased during the 1990s. Fluxes of nitrogen and phosphorus have been affected and disturbed by many factors associated with anthropogenic activities, but primarily by domestic and industrial waste water effluents. Today, the agency in charge of managing La Tordera is the Catalan Water Agency (ACA). Attached to the Department of the Environment and Housing (DMAH), this public organisation is the only water administration of the Catalan Government with full authority on the intern catchments of Catalonia (i.e. river catchments that lie entirely within Catalan borders). From the end of the 1990s, management by the Catalan government (Table 1) of agricultural and industrial activities, and of demographic growth, was gradually reinforced. In accordance to the Urban Waste Treatment Directive (UWWTD, 91/271/EEC), the Catalan government developed and implemented strategic plans for the treatment of all urban and industrial waste waters (in 1995 and 2002 for urban waste waters, and in 1994 for industrial waste waters)

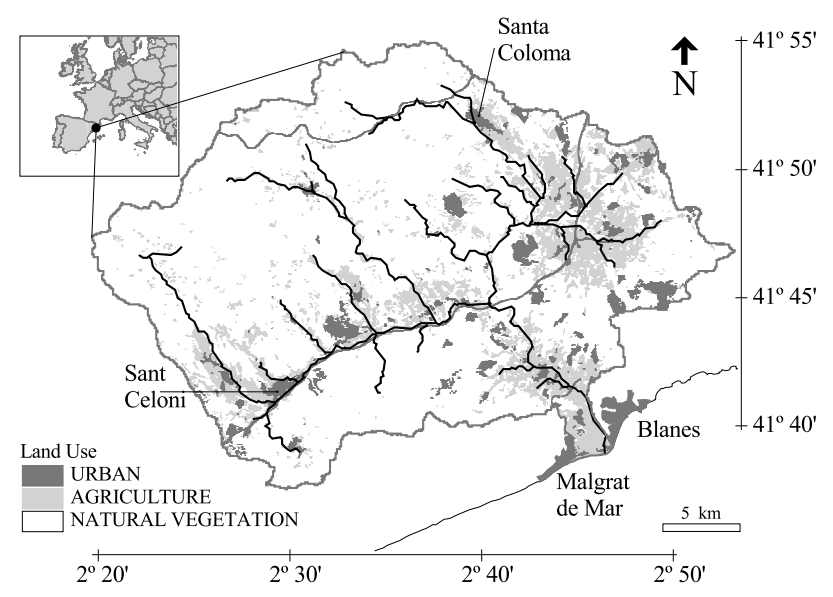

Fig. 1. Location of La Tordera catchment in Catalonia, showing main land uses.

(ACA, 2002, 2003). Today, waste waters from all towns with more than 2000 inhabitants are treated, and point sources of nutrients have decreased substantially since the first plan for urban waste water was initiated (Jubany, 2007 ${ }^{1}$ ) (ACA, 2005; Diputació de Barcelona et al., 2005). However, agricultural diffuse nitrogen emissions remain largely unaddressed. For example, at Forgars monitoring station, $14 \mathrm{~km}$ upstream of the mouth, the median concentration of soluble reactive phosphorus has decreased from $0.22 \mathrm{mgP} / 1$ in $1990-1995$ to $0.07 \mathrm{mgP} / \mathrm{l}$ in 2000-2004, whereas the mean concentration of nitrate has decreased only from 1.81 to $1.32 \mathrm{mgN} / \mathrm{l}$ between the same two periods.

\section{Methodology}

The scenarios developed in this paper fall into the category of explorative and external scenarios in the typology proposed by Börjeson et al. (2006). Indeed, they are elaborated with a long time-horizon (2030) and are based on forces which are not directly under the control of the stakeholders. However, the scenarios share some qualities with the normative scenarios as defined by van Notten et al. (2003), namely a consideration of the interpretations, values and interests of scenario developers. We sought to respond to the question "What can conceivably happen to the development of external (socio-economic) driving forces that impinge on nutrient emissions to La Tordera river?" Scenarios were developed during a one-day workshop with selected stakeholders. This technique allowed us to generate, collect and work with ideas and to structure thinking with a view to produce immediate results. Based on the comprehensive views

\footnotetext{
${ }^{1}$ Jubany, J.: Anàlisi de la qualitat biològica de la conca de la Tordera a partir de macroinvertebrats. A: edited by: Boada, M., Mayo, S., and Miralles, M., Els sistemes socioecològics de la conca de la Tordera, Barcelona, ICHN, submitted, 2007.
} 
Table 1. The different sectors of activity are indicated by the abbreviated letters as follows: A, Agriculture, U/T, Urbanisation/Tourism, and I, Industry. Regarding the urban sector, 3/4 of the participants were citizens of the catchment. Participants to the scenario development workshop for La Tordera catchment.

\begin{tabular}{|c|c|c|c|}
\hline & Stakeholders & Sectors & Websites \\
\hline $\begin{array}{l}\text { Public Organisations/ } \\
\text { Institutions }\end{array}$ & $\begin{array}{l}\text { - Catalan governmental departments: } \\
\text { - Catalan Department of Agriculture and } \\
\text { Fisheries (DARP), } \\
\text { - Catalan Department of the Environment } \\
\text { (DMAH, Prevention and control section), } \\
\text { - Department of Territorial Policy and } \\
\text { Public Works, } \\
\text { - Water agency (ACA), } \\
\text { - City halls: Territorial and town planning } \\
\text { divisions }\end{array}$ & $\begin{array}{l}\text { A } \\
\text { I } \\
\text { U } \\
\text { U } \\
\mathrm{U}, \mathrm{T}\end{array}$ & $\begin{array}{l}\text { - http://www.gencat.net/darp/ } \\
\text { - http://mediambient.gencat.net/ } \\
\text { - http://www.gencat.net/ptop/ } \\
\text { - http://www.mediambient.gencat.net/aca/es } \\
\text { - http://www.ajmalgrat.es/ }\end{array}$ \\
\hline
\end{tabular}

of scenario planning structure presented by Mercer (1995) and the European Environmental Agency (EEA, 2001), we conducted the workshop by applying a combination of the steps of two methods, "Futures Skills" of Graham H May (http://www.futuresskills.co.uk) and "Idon Visual Thinking" (Galt et al., 1997), for the participatory generation of scenarios. These are highly effective, quick and straightforward techniques. One of us had already experience in applying the latter method to the management of biological invasions (Rodríguez-Labajos, 2006).

The workshop for scenario planning was conducted in a neutral place within the catchment (i.e. a music school in the town of Sant Celoni, Fig. 1) and led by three of us (FC, BLL and JLR) plus another person in charge of taking notes. Scenarios were developed through a participatory process with selected representatives of stakeholders. Preparation for the workshop included an analysis of nutrient emissions and concentrations in La Tordera over the last decade, an evaluation of the socio-economic system relevant to nutrient emissions to the river, the identification of stakeholders and a set of interviews with selected representatives of stakeholders (Fig. 2).

The generation of scenarios was based on a structured set of activities, which involved the following steps: (1) identification and analysis of driving forces, (2) identification of key uncertainties, (3) generation of clusters of driving forces and scenarios, and (4) development of storylines. All activities in plenary and separate groups were tape-recorded.
3.1 Identification of stakeholders and selection of participants

We started by identifying the key stakeholders (Fig. 3) inspired by the "Shaping actors - shaping factors" method, used for the first time for "The European Challenges post1992" (A. Jacquemin and D. Wright, 1994). We based this process on our initial analysis of the nutrient emissions, former project reports (Tàbara and Saurí, 2004; http: //www.observatoririutordera.org/), recommendations from academic experts and local informants, and Internet research. Stakeholders were selected to include both public and private sectors, groups with a direct effect on water quality (nutrient emitters), local and regional administrative departments with a stake in the development and implementation of policy relevant to nutrient emissions, and locally represented organisations involved in environmental conservation. Then, we explored and analysed the complex human-ecosystem interactions with the use of a series of interviews that we conducted with representatives of all the main social actors of La Tordera catchment (Fig. 3). The results were organised in an analytical framework indicating the role, pressures and impacts of all social actors as suggested by Smeets and Wetering (1999) and the WFD (2002a). Among all stakeholder groups, the most powerful ones in terms of their influence on decision-making are the Catalan Governmental Departments, the ACA, and the city halls (Fig. 3).

The selection of participants is crucial for the success of any participatory process; this is why we paid special attention to this phase (Wollenberg, 2000; Kok et al., 2006). We 


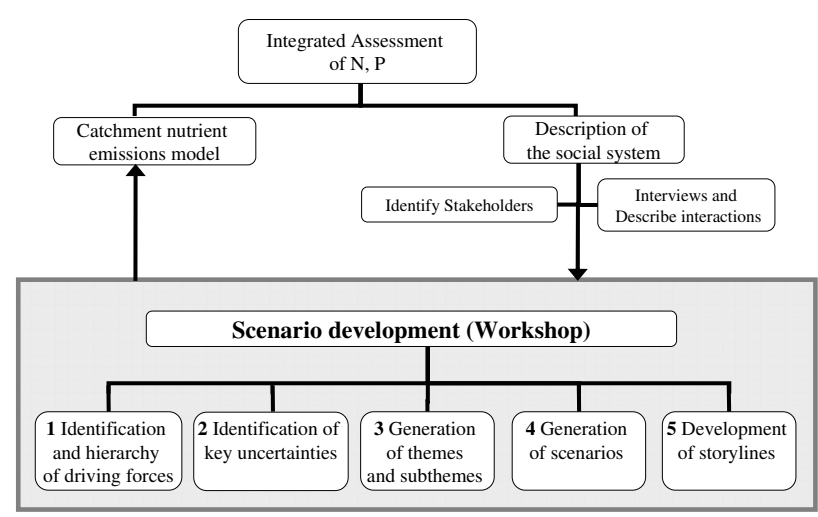

Fig. 2. Flowchart of the methodological process for local scenarios development through a participatory process.

selected participants based on our list of stakeholders and the results of personal interviews. We sought participants with knowledge on the problem at stake who expressed an interest in being involved in this exercise, had an open attitude and were communicative. Whenever possible, we sought persons who were involved in decision-making processes and could influence the implementation of the WFD in the study catchment. At the same time, we strove to have an even representation of the identified stakeholders. The workshop was held with 12 participants representing the main stakeholders (Table 1).

\subsection{Main steps of the scenario development}

The first step, i.e. the selection and analysis of the driving forces, was done in three phases. First, prior to the scenario development workshop, a series of face-to-face interviews with participants was conducted to develop commitment in the research and to provide a preliminary set of the main driving forces. Second, during the workshop, we started with a presentation of the participatory process and its context. This was followed with a brainstorming exercise in three separate groups defined by sectors of activity (i.e. agriculture, industry, and urbanization and tourism). Finally, a plenary brainstorming session was used to identify the main relevant driving forces at a broader, cross-sectoral level; these included industrial, agricultural, economic, political, technological, legal and societal trends (see Sect. 4.1). Relevant driving forces were written on "Post-it" notes and placed on the wall. Participants were asked to assess the extent to which these driving forces were influencing sectoral evolution and affecting $\mathrm{N}$ and $\mathrm{P}$ loads, and hence water quality, and to think about current trends for each relevant factor.

One of the main aims of the participatory scenario method is to raise awareness about the unpredictability of the future and to acknowledge the fact that making decisions in the present has implications for the future. Therefore, participants, working together as a group, were asked to assess

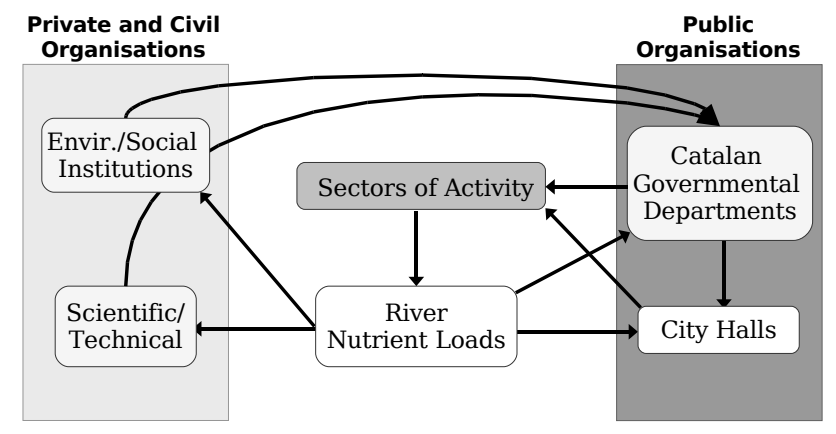

Fig. 3. Schematic representation on the main stakeholders identified for La Tordera catchment relative to nitrogen and phosphorus emissions. Arrows indicate the main directions of influence between stakeholder groups. Sectors of activity (agriculture, industry, and urbanisation plus tourism) affect nutrient emissions directly.

each driving force on two scales: uncertainty vs. predictability, and degree of relevance with regards to water quality and the selected time interval. The aim was to classify and place the driving forces on a grid with axes running from high to low uncertainty, and high to low relevance. Driving forces that were not considered important were discarded. Those which were qualified as important but relatively predictable (e.g. demography) were kept but only to be included in all scenarios. Therefore, the generation of scenarios was not based on these driving forces, but only on a limited number of important and unpredictable driving forces. At this point, it was essential to assess whether any linkages between driving forces existed, and to rule out any impossible scenarios. This entire process ensured that neither predictable nor impossible scenarios were considered.

After a creative and participative brainstorming, stakeholders conceptualised and qualified two main thematic groups of driving forces. These two main themes based on the socio-economic driving forces that have an influence on nutrient emissions to La Tordera river were then used to generate two subthemes for each of the main themes. Subthemes define two distinct alternatives (i.e. extremes of the state). Thus, by combining themes and subthemes we obtain a matrix allowing the creation and development of coherent, internally consistent, and plausible descriptions of four possible future scenarios (see Sect. 4.1 and Table 2). By emphasising the uncertainty of the future but avoiding the confusion of too many alternatives, the potential of the participatory technique can be realised. The main characteristics of each future were underlined and developed. The last step consisted in conferring a descriptive and catchy title to characterise each scenario. Titles help to remember each scenario and facilitate communication about them.

The participants, in a plenary session, learnt together to narrate one scenario to facilitate the development of the storylines. The narrative of a scenario seeks a short description of its evolution as a history explaining the driving forces and 
Table 2. Scenarios generated by the participants to the workshop based on the combination of two themes and two alternative subthemes for each of these themes. The scenario "Inertia" is identified as a "Business as Usual" scenario (BAU). See text for full narratives for each scenario.

\begin{tabular}{|c|c|c|c|}
\hline & & \multicolumn{2}{|c|}{ Sectoral Interaction } \\
\hline & & The market governs & $\begin{array}{c}\text { Coexistence of market and } \\
\text { territory }\end{array}$ \\
\hline \multirow{2}{*}{$\begin{array}{l}\text { Political } \\
\text { Planning }\end{array}$} & Short-term & $\begin{array}{ll} & \text { Inertia } \\
\text { - } & \text { Lack of coordination } \\
\text { - } & \text { Utilitarian management } \\
\text { - } & \text { Growth and weak control } \\
\text { - } & \text { Intensive activities and based on } \\
\text { - } & \text { High level of contamination }\end{array}$ & $\begin{array}{ll} & \text { Pact for subsistence } \\
\text { - } & \text { Adaptation } \\
\text { - } & \text { Fast growth with local control } \\
\text { - } & \text { Cooperation, but lack of } \\
\text { management } \\
\text { - } \\
\text { Medium contamination }\end{array}$ \\
\hline & Long-term & $\begin{array}{l}\text { Minimum rules } \\
\text { - Stronger regulations and investment, } \\
\text { but local conflicts } \\
\text { - Good intentions, but passive } \\
\text { cooperation } \\
\text { - Low-Medium contamination }\end{array}$ & $\begin{array}{ll} & \text { Sustainability } \\
\text { - } & \text { Equilibrium between society and } \\
\text { environment } \\
\text { - } & \text { Growth but control } \\
\text { - } & \text { Investment } \\
\text { - } & \text { No (or low) contamination }\end{array}$ \\
\hline
\end{tabular}

sequence of events that lead to the scenario situation. Using several elements, i.e. population and economic growth, technological development and environmental protection, participants explained the plausible evolution of each factor selected in the previous step and qualitatively described their trends.

After this learning experience, participants, as separate working groups, elaborated narratives for the three remaining scenarios. After joint deliberation, contents were synthesised and confirmed. Then, the workshop leaders built the storylines, and, a few days after the workshop, we asked participants to revise and approve them, as part of the follow-up to the participatory process.

\subsection{Semi-quantitative evaluation of scenarios}

To help quantifying the impact of the various scenarios on nutrient emissions within a modelling environment, socioeconomic scenarios need to be translated into a set of quantitative scenarios in a form suitable for input into a catchment model. In this study, the catchment model MONERIS (Modelling Nutrient Emissions in River Systems) will be used at a later stage. MONERIS is an empirical, semi-distributed model that provides estimates of nitrogen and phosphorus annual loads and partitions loads according to the main point and diffuse sources in the catchment (Behrendt et al., 2000;
Riera et al., 2002). Our aim here was to relate the trends listed for each socio-economic scenario to the list of input data used by the model MONERIS in order to examine expected impacts on emissions for each scenario.

To perform this translation, we marked the trend expected for each emission pathways under each of the four socioeconomic scenarios developed during the workshop. We then asked workshop participants by e-mail to comment on our initial evaluation and to suggest modifications. When we felt the interpretation of trends was ambiguous, we specifically asked participants to address those cases.

\section{Results}

Results of the main steps presented in the methodology for the generation of scenarios include the identification of driving forces and key uncertainties, the definition of the themes and subthemes that generated four scenarios, and the development of storylines.

\subsection{The scenarios}

Participants identified the following list of driving forces as key to the future of the catchment, yet of uncertain evolution: agricultural use change, decrease of the agricultural output production, population growth, urban pressure, tourism 
expansion, relocation of industrial production, planning of industrial estates, water allocations, climate change, regulations, and administrative policy.

After agreeing on the major driving forces that were relevant for La Tordera catchment, participants came up with two main themes for the generation of scenarios: "Political Planning" and "Sectoral Interaction", which are nonetheless quite general. The former embodied all driving forces related to the regulatory framework and the development of policies at local and regional levels addressing demographic changes, labour standards, and environmental concerns (e.g. water allocations). The latter considered all the aspects of sectoral development governed by economic development, i.e. market dynamics and competitiveness. For each of these two themes, two alternatives were defined. These were, for the political planning theme, an emphasis on either short term or long term planning, and, for the sectoral interaction theme, an economic environment in which the market rules versus one presided by a balance between economic and territorial development, including conservation. The combination of themes and subthemes produced four scenarios (Table 2), for which participants drafted the following narratives based on population growth, economic growth, technological development, and environmental protection.

\section{Scenario I: Inertia}

This scenario is driven by short-term planning. Sectoral development is mainly governed by market dynamics and competitiveness. The leitmotiv for this forward-looking approach is "productivity" instead of a model of production based on "Quantity and Quality" and sustainability criteria. It was identified by participants as a business-as-usual scenario (BAU).

In this scenario, both the growth of urban areas and the expansion of tourism respond only to economic criteria, i.e. property profit. Following current trends, the urban sector thrives not only along the coastal zone, but also in the inland part of the catchment.

Traditional agriculture loses area or disappears, with the exception of intensive farming of ornamental plants, already an established activity. Because of a lack of information and education about environmental consequences, and of market pressure, agricultural practises such as the use of fertilisers are intensified to increase productivity and boost economic returns.

In spite of regulations, the number of water allocations increases due mainly to increased water consumption and demand. Regulations, which already are considered to be obsolete and not properly enforced, do not adapt fast enough to a constantly changing situation. The authorities responsible for drafting and enforcing these regulations do not succeed in generating a consensus to oppose the inertia.

Following current trends, the industrial sector progressively abandons the production of goods in favour of logistics, service production and intellectual services, i.e. the tertiary and quaternary sectors of industry.

\section{Scenario II: Pact for subsistence}

This scenario combines actions in the territory driven by short-term planning with a sectoral performance that attempts to develop the market while taking into account territorial development. The necessities of the short-term planning induce the intervention of the public administration, which takes action as problems emerge.

This scenario is characterised by strong population growth due to the proximity and expansion of the metropolitan area of Barcelona, increased transport connexions, immigration and the strong growth of tourism. As a result, urban pressure continues to grow at a sustained rate and second homes are converted to primary residences.

The agricultural sector remains stable thanks to conventional practices supported by a moderately successful territorial planning. The agricultural configuration, practices and yield remain unchanged. An attempt is made to curb the negative impacts of the sector.

Water allocations show regular and moderate growth. In spite of regulations, the current trend towards an overexploitation of La Tordera aquifer is maintained and may become critical. Public authorities still focus on short-term planning and cannot avoid these negative outcomes in spite of the implementation of monitoring and enforcement measures on water uses.

Only industries with access to adequate financial resources are able to specialise and survive the pressures towards relocation. The autonomous authorities do not limit effectively the escalation of industrial estates (a current trend), delegating this task to the local authorities.

\section{Scenario III: Minimum rules}

This scenario combines actions in the territory driven by long-term planning with a sectoral development governed mainly by market dynamics.

This scenario is characterised by a moderate growth of the population as a result of immigration and conversion of second homes into primary residences, which initially contributes to the expansion of the urban area. Subsequently, the trend changes towards protecting the urban landscape and managing the social needs and demands of the newly established population. This leads to a more compact urban design with restrictions on the height of buildings. Second homes in dispersed developments tend to change into main residences; "sun and beach" tourism remains as today.

Agricultural production is aided by protection policies and guarantee-of-origin devices that place an added value on the local products. Nonetheless, it loses ground to the exploitation and management of forests.

Environmental protection policies and water supply planning together reduce water allocations in La Tordera 
catchment. However, market pressures tend to increase water demand, which is eventually met by resorting to interbasin water transfers. The Catalan government strengthens the enforcement of environmental regulations, and this generates competence conflicts with the local authorities, which are only solved through supranational guidelines or legislations, such as European policies. The social actors have an ambivalent position in relation to environmental policies. On the one hand, they request improvements in environmental quality. On the other hand, they refuse to bear economic and social costs that can foster such improvements. In this scenario, stakeholders understand that environmental costs should comprise an investment towards improving standards of living.

The economic and political situation leads to a moderate increase of industrial estates and leisure centres on country lands. At the same time, there is a trend towards the relocation of industrial activities which cannot comply with environmental regulations. A decline of the primary and secondary industrial sectors in favour of logistics is accompanied by lower production of contaminants, but brings with it other negative environmental externalities (e.g. an increase in traffic exacerbating air pollution).

\section{Scenario IV: Sustainability}

This scenario combines actions in the territory driven by long-term planning with a well-balanced sectoral performance that attempts to develop the market while taking into account territorial development.

In this scenario, urban change is characterised by the growth of the local population as second homes are converted into primary residences thanks to prosperous economic and labour opportunities. On the coast, the model of mass tourism brings about irreversible changes in the landscape; in contrast, in the mountain areas an ecological tourism model is eventually implemented contributing to the preservation of the environment and the rural landscape. Although the economic impact of this activity is not very significant in the region, it stimulates the services sector in the rural areas.

Thanks to agro-tourism activities, the agricultural sector benefits from more leeway in its mode of operation. However, doubts are raised regarding the future of this sector. Agriculture continues to be highly dependent on subsidies to guarantee the preservation of the landscape and the environment. The implementation of devices to increase the presence of agricultural producers in the distribution and commercialisation of their products alleviates this problem. Agricultural subsidies are increasingly justified by the role taken by farmers as stewards of the rural environment.

Water allocations are restricted in accordance with urban planning. A hefty but necessary investment is committed to improving waste water treatment.

\begin{tabular}{|c|c|c|c|c|}
\hline \multirow[b]{2}{*}{$\begin{array}{ll}\text { Pathways } & \text { Scenarios } \\
\end{array}$} & \multicolumn{2}{|c|}{ SHORT TERM MANAGEMENT } & \multicolumn{2}{|c|}{ LONG TERM PLANNING } \\
\hline & INERTIA & $\begin{array}{c}\text { PACT FOR } \\
\text { SUBSISTENCE }\end{array}$ & $\begin{array}{l}\text { MINIMUM } \\
\text { RULES }\end{array}$ & SUSTAINABILITY \\
\hline \multicolumn{5}{|l|}{ Point sources } \\
\hline $\begin{array}{l}\text { Waste water treatment plants } \\
\text { (WWTP) }\end{array}$ & $\not$ & $\rightarrow$ & $\rightarrow$ & $x$ \\
\hline Direct industrial discharge & $\rightarrow$ & $\rightarrow$ & $\rightarrow$ & $x$ \\
\hline \multicolumn{5}{|l|}{ Diffuse pathways } \\
\hline Direct Atmospheric inputs & $\rightarrow$ & $\rightarrow$ & $y$ & 一 \\
\hline Surface runoff & $x$ & 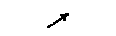 & $\rightarrow$ & $\searrow$ \\
\hline $\begin{array}{l}\text { Erosion (e.g.: } \mathrm{N}, \mathrm{P} \text { content in } \\
\text { topsoil) }\end{array}$ & $\not$ & $\rightarrow$ & $x$ & $x$ \\
\hline $\begin{array}{l}\text { Groundwater and tile drainage } \\
\text { via } \mathrm{N} \text { surplus in agricultural land }\end{array}$ & $x$ & $\gamma$ & $\rightarrow$ & 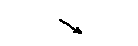 \\
\hline Urban diffuse sources & $\rightarrow$ & 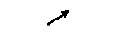 & $\rightarrow$ & $x$ \\
\hline
\end{tabular}

Fig. 4. Compact representation of the evolution of $\mathrm{N}$ and $\mathrm{P}$ loads expected for each of the main emissions pathways in the model MONERIS for the four socio-economic scenarios. For each scenario, expected trends of $\mathrm{N}$ and $\mathrm{P}$ loads relative to current conditions are indicated by arrows as follows: increasing trend; no significant change; and decreasing trend.

Driven by globalisation and local environmental regulations, industries relocate away from the catchment. This offers an opportunity to change the industrial fabric and promote a services industry that is more environmentally friendly. Nonetheless, industries of the secondary sector remain because a significant proportion of existing companies tend to adapt to environmental regulations as long as they remain economically successful.

\subsection{Interface with the catchment model MONERIS}

Figure 4 summarizes, for each of the main pathways, the trends in nutrient emissions that are to be expected under each of the four scenarios developed in this study. Scenarios for modelling nutrient emissions are presented in order of decreasing impact on the river. Thus, the scenario "Inertia" or BAU is expected to results in an increase in nutrient emissions, thereby worsening water quality, while the scenario of sustainability provides the largest improvement in environmental conditions relative to the current situation. Both the "Inertia" and "Pact for subsistence" scenarios suggest a decrease in the overexploitation of the aquifer. In spite of that, and an important decrease or no significant change, respectively, of extensive agriculture, the overall trend suggests an increase in emissions mainly due to the growth of urban areas, the expansion of tourism and the increase of water allocations. As for the two main characteristics related to the erosion and diffuse transport through groundwater flow pathways, i.e. phosphorus content in topsoil and nitrogen surplus, we observe an increase in the emissions into the river under the BAU scenario. Moreover, except for the "Sustainability" scenario, although the socio-economic scenarios suggest fluctuations in the evolution of industrial and urban point sources and urban diffuse sources, the general trend for these emission pathways seems relatively unimportant. 


\section{Discussion}

\subsection{Participatory scenarios and nutrient flows modelling}

To prevent further pollution and to protect and enhance the ecological state of streams and rivers, it is necessary to define and develop relevant sets of water management alternatives for the future of the catchment through the implementation of environmental policies. This strategy should ideally harmonise the conflicting needs of the stakeholders in the catchment and allow us to find the best agreement between the use and conservation of the ecosystem. Developing local socioeconomic scenarios through a participatory process can contribute, at a later stage, to modelling exercises based on the evolution of nutrient emissions into the river in the mid-term (i.e. about 30 yrs ahead) to assist catchment management at the same time that it underlines and promotes in an implicit way a learning process for both researchers and participants and fosters the communication among stakeholders.

The development of scenarios generated four realistic visions of the future based on uncertain driving forces. Throughout the participatory process, stakeholders had to think about uncertainties and consider the possibilities of change. Indeed, they were expected to make manifest the connections between nutrient fluxes in the river (and, more broadly, water quality and ecological status) and both local and regional socio-economic trends or changes and management actions. In a first evaluation of scenarios by the participants at the end of the workshop, all scenarios seemed to show remarkable similarities; this was probably due to the existence of a few elements that were common to the four scenarios and corresponded to important trends on which participants tended to agree, i.e. trends that exhibited limited uncertainty. However, the development of storylines and the semi-quantitative evaluation of the consequences of each scenario for nutrient emissions helped to highlight the differences among scenarios.

The generation of narratives explaining the outcome of each scenario and the reasons for the proposed situations, allowed participants to give value and consistency to the scenarios. Taking into account all current and relevant driving forces having an influence on the evolution of each economic sector, participants agreed that the scenario of sustainability, which, out of all four scenarios, was obviously the preferable future for La Tordera catchment, could be realised.

Although the results of a modelling exercise were not the purpose of this paper, we do discuss the translation of storylines into meaningful semi-quantitative nutrient emission scenarios. Applying socio-economic scenarios such as the ones presented here to a physical catchment model to explore their effect for nutrient emissions requires their translation into quantitative indicators useful to feed the model. Quantification of narratives using a set of indicators is subject to debate. Indeed, as Berkhout et al. (2002) explains, storylines are the result of stakeholder's future views based on uncertainty while the concept of quantitative analysis relies on an idea of neutrality and accuracy, deceptive as this may be. The first translation of each scenario into quantitative indicators for a model facilitated the interpretation of scenarios as it forced us to interpret the storylines in the form of explicit trends that could be communicated objectively, thus granting more consistency to each scenario. Later on, when values (rather than trends) are assigned to each indicator for impact assessment, scenarios might be viewed with more credibility. Nonetheless, it will be important to keep in mind that values are not definitive, but indicative and illustrative (Berkhout et al., 2002).

A further challenge is to make scenarios spatially-explicit for use with a semi-distributed catchment model. We propose to develop quantitative scenarios relative to the "inertia" (BAU) scenario, defined as the projection of current trends based on an analysis of changes over the last decade. This stage of the project will need again the collaboration of stakeholders and experts (e.g. ACA) via e-mail or personal interviews. Maintaining the communication with stakeholders over the process will ensure that they see an outcome of their contribution and feel more involved, which is also a measure of success in participatory integrated analysis (Ridder and Pahl-Wostl, 2005).

\subsection{Assessment of the process: results, learning and inte- gration of languages}

Experiences in scenario building, e.g. urban development and sustainability and biological invasions, have revealed that, even if results provided during the process are important, there is value in the process itself (Özkaynak, 2005; Rodríguez-Labajos, 2006). The special attention dedicated to the identification of stakeholders and the selection of workshop participants is essential to guarantee the quality of the process (Burt and van der Heijden, 2003). Although the four scenarios produced by the participants are common sense, results would probably differ, yielding a different set of scenarios, if the workshop were to be repeated with a different set of players or through a close, common senseapproach. Are these scenarios therefore "better" than what a closed session would have produced? Who is to judge? What is clear is that by not doing the participatory process, we all (stakeholders and researchers) would have missed on a precious opportunity to learn and be involved in or communicate a research exercise, modest as this may be.

While the identification of stakeholders needs to be comprehensive, striving to include all interested social actors, participants (i.e. individuals representing a particular stakeholder), also need to be selected so as to ensure their commitment to the process and their willingness to discuss constructively around conflicting issues with other participants. In the context of the Rönnea Catchment Dialogues for the Swedish Water Management Research Program (VASTRA), which focussed on the eutrophication problem, participants 
argued that their willingness to be involved was more likely to work out well in an area where they have personal stakes (Jöborn et al., 2005). Leeuwis (1995) also endorsed this statement with a case study where he observed that the diversity of interests among stakeholders, which is a preliminary selection problem, became an obstacle to reach a consensus.

Moreover, the current situation and the background, knowledge and experience of participants have a strong influence on their ability to think about the future and truly imagine futures, and therefore the risk exists for participants to forecast rather than think more creatively about scenarios. Throughout the process, it was necessary to use and integrate many languages and forms of knowledge. Indeed, the advantages of IEA are predicated on the contribution of knowledge from multiple disciplines (Janssen and Goldworthy, 1996; Parker et al., 2002). But this comes with a price. Heterogeneity in backgrounds and fields of expertise does not facilitate the engagement of participants in the process, because they may feel uncomfortable and insecure (Rotmans et al., 2000). Thus, involving people from different fields can lead to communication problems. Indeed, since each field has its own way of thinking and speaking, it is possible that some words might be interpreted differently across various fields. Here, the role of the workshop leaders as facilitators was crucial. Their goal was to create a friendly and encouraging atmosphere for discussion and to watch out for misunderstandings that could have stymied progress. Thus, they were informed by the opinions and sentiment of a diversity of stakeholders that allowed to guarantee that the scenarios used in modelling nutrient fluxes into the future did not simply reflect the researcher's biases. Yet the value of the formal process of scenario development presented in the paper lied precisely in its ability to facilitate an open discussion and the free and active involvement of all participants.

Interactions and discussions between participants generated strong disagreements, which were part of the process of the identification and selection of driving forces, both at the sectoral and territorial level. The 2030 horizon allowed participants to put current conflicts aside and think more dispassionately about the future of the catchment; therefore, disagreements were not as strong as if the scenario building were based on a short-term horizon. But even though participants argued to support their points of view, mostly in relation to standing conflicts and the current political context, discussions to classify key driving forces influencing water quality also revealed a common willingness to come to an agreement, and allowed to create a trusting atmosphere between the various stakeholders involved in this process. Therefore, disagreements enhanced the group's creativity and promoted scenario development. This shows that interdisciplinary co-operation can help to think about the future and generate possible futures (Joss, 2002; Ledoux, 2005).
5.3 Challenges of and lessons from the participatory process

Difficulties during the process of scenario building and a lack of guarantee that results will be obtained have been recognized as inherent to this participatory exercise and contribute to the learning process, which is one of its benefits (Leeuwis, 1995).

Given the time horizon for our scenarios (i.e. the 2030), participants could have shown a tendency to focus on unrealistic scenarios and therefore miss the objective of the workshop: developing realistic alternative views of the future. This tendency could be avoided by focusing on the goal, promoting the participation of all stakeholders and keeping their attention throughout the participatory process.

Even if we were paying special attention to keep the workshop on track, participants did not always focus on the problem at stake, i.e. developing socio-economic scenarios with a view to exploring their impact on nutrient emissions and contributing to the sustainable management of the anthropogenic sources of these nutrients. A few participants tended to slow down the process by focusing on their own sectoral problems or current interests, and thus tended to deviate the meeting from its goal. This was probably due to the fear of loosing credibility, an inability to deal with the problem at stake, or a lack of knowledge or mutual understanding. However, it did not appear to us that participants were trying to divert the focus from our main objective. It might have just been that they wanted to ensure that their own interests would be reflected in the storylines. Thus, as facilitators we tried to redress the discussion and stimulate a more imaginative thinking about the future.

Other difficulties that we identified in the process of scenario building were that (1) it was sometimes hindered by our retention capacity; and (2) there was always a risk to fall back on forecasts, and avoid drivers that might become important in the future.

The process was sensitive to the current economic and political conditions, and consequently the driving forces identified were mainly based on current trends. This was probably due to a difficulty inherent to the process, which highlights the inability to "think outside the box", i.e. think about driving forces and trends that participants are not familiar with. In these conditions, it seemed difficult to consider surprises, limiting the scenarios to variations of current trends. Indeed, in the multi-scale scenario work within the MedAction project, which emphasised scenario development at different scales and also the relations between scales, Kok et al. (2006) came to the conclusion that stakeholders had difficulties to work on large-scale surprising developments; also, Burt and van der Heijden (2003), working on scenario development with small and medium sized enterprise managers for strategic management and learning process, agreed with Kok et al. (2006) that stakeholders tended to prefer thinking in terms of a forecast or "single future", feeling more 
comfortable with either small changes or large-scale developments that are close to daily life.

The issue of climate change illustrates these points. Although it is widely accepted that "climate change" will likely have a significant impact on hydrology and nutrient export in the mid term (Ledoux et al., 2005; Wade, 2006), participants did not select it as a relevant and uncertain driving force. When the workshop leaders introduced it as a factor and asked participants to consider it when writing up narratives for the scenarios, it was still avoided. Although all participants agreed on its relevance and uncertainty, they still felt unable to think about how it might affect the catchment and saw it as an external force outside their experience and control. We also asked for hypothetical or surprise driving forces (or factors), but no convincing response was given by the participants.

The follow-up to the participatory workshop represented an additional obstacle. Although the one-day workshop was successful, it did not represent a guarantee that the followup to the scenarios results, i.e. individual evaluation to validate scenarios content and pre-evaluation of model indicators, would be performed. The follow-up was based on the continued good will and voluntary participation of the stakeholders, since they had no personal benefit in contributing to this exercise. Outside of the workshop context, participation was not as large as we had expected, even though stakeholders previously expressed their willingness to respond to our request to provide us with feedback. In contrast, Kok et al. (2006) reported a positive follow-up with a high rate of response to their questionnaire. The reason for this difference in response rate may lie in the technique used to get feedback. We decided on an e-mailed questionnaire with open questions, a method that relied too heavily on the willingness of respondents to think through the information sent to them and organize their ideas. Personal interviews would have elicited more information, but at a higher cost.

Based on our experience, we can propose a number of changes to improve participatory processes at the local scale. Firstly, it might be advantageous to organise the activities in a series of half day sessions; this might facilitate the progress of the activities, allowing stakeholders to better interact among themselves and granting them more time to express and defend their points of view and to debate contentious issues (Kok et al., 2006). Also, it is obvious that a participatory exercise initiated by the stakeholders themselves and facilitated by an external and professional moderator would have been very different - starting with the objectives. Thus, the collaboration of a facilitator actively involved with stakeholders would be very helpful to assist in such a process. When working on the future of La Tordera catchment, the workshop leaders were responsible for both managing and facilitating the workshop. During plenary activities, the leader in charge of the participatory process was also responsible for supporting interaction and communication between participants, which is how the standard model defines the role of a facilitator. When the activities required separate working groups, everyone in the workshop team assumed and played the part of the facilitator as best as he or she could. Thus, we tried to be actively involved with stakeholders and make them think and justify their choices by means of questions, as Mumford (2001) and Leeuwis (2000) suggest for the role of the facilitator. When disagreements arose, we attempted to enhance discussion, then refocused participants back to the topic. But even if we tried to be neutral, and attempted not to influence the process, willingly or unconsciously, with our preconceptions and biases, the simple fact that we, i.e. the researchers, came from ecology and environmental sciences university departments undoubtedly carried some weight.

In Spain, as perhaps in Mediterranean countries in general, participatory processes are increasingly being used to address environmental issues (Özkaynak, 2005; Kok et al., 2006; Rodríguez-Labajos, 2006), as it is recommended not only by current legislation such as the Water Framework Directive, but also by grassroot movements such as the New Culture of Water. However, experiences are still scarce, the process is unfamiliar to participants, and relying on a professional facilitator is not common, and even less considered as an essential element for this kind of process. Thus we see the workshop as a pilot exercise that stakeholders and management agencies, both represented at the workshop, might benefit from.

\section{Conclusions}

In the context of an integrated assessment of nutrient flows, the scenario method adapted to our case study for the development of socio-economic scenarios for a Catalan river catchment proved to be an effective medium for interactive and structured thinking. Even though we encountered some weaknesses and challenges throughout the process (e.g. the structure of the workshop, the need for a facilitator, and the follow-up procedure), this technique allowed us and the participants to recognise the role of and need for stakeholders' participation as key to the generation of meaningful scenarios. No guarantee of success exists for a participatory process of scenario building. Despite the potentially conflicting nature of the environmental issues, the process is more likely to generate possible views of the future if there are both a trusting atmosphere and willingness to participate among the stakeholders involved. Thanks to the effort dedicated to the development of storylines, the interdisciplinary co-operation, and the group's creativity, participants conferred meaning and consistency to the scenarios. The use of scenarios as a participative tool for defining catchment management strategies uncertainty is essential (Middelkoop et al., 2000; Postma and Liebl, 2005). The translation of the generated scenarios into meaningful semi-quantitative nutrient emission scenarios allowed preparing the base for the subsequent generation 
of quantitative and spatially-explicit scenarios with the use of a catchment nutrient emission model. This successful pilot process might encourage catchment managers and planners to integrate scenarios and participatory processes into their toolbox.

Acknowledgements. The authors would like to thank D. Saurí (Autonomous University of Barcelona) for his advice and support, as well as all the participants in the workshop and local authorities. Funding for this project was provided by the Institute of Environmental Sciences and Technology (ICTA, UAB) and the European Project Eurolimpacs (FP6-SUSTDEV, project reference 505540). Frédérique Caille benefited from an IQUC and Marie Curie scholarship, respectively from the Catalan government and the European Community for the Sense research school programme.

Edited by: S. Barles

\section{References}

ACA (Agència Catalana de l'Aigua): Pla de sanejament d'aigües residuals urbanes (PSARU 2002), Departament de Medi Ambient de la Generalitat de Catalunya, 2002.

ACA (Agència Catalana de l'Aigua): Programa de sanejament d'aigües residuals industrials (PSARI 2003), Departament de Medi Ambient de la Generalitat de Catalunya, 2003.

ACA (Agència Catalana de l'Aigua): Caracterizació de masses d'aigua i anàlisi del risc d'incompliment dels objectius de la Directiva Marc de l'Aigua (2000/60/CE) a Catalunya, Documento Impress, Available online at: http://mediambient.gencat.net/aca/ $\mathrm{ca} /$ planificacio/directiva/impress.jsp, Departament de Medi Ambient de la Generalitat de Catalunya, 2005.

Arrojo Agudo, P.: El reto ético de la nueva cultura del agua, funciones, valores y derechos en juego, edited by: Paidós, Barcelona, 2006.

Bailey, P. D., Gough, C. A., Hadwick, M. J., and McGranahan, G.: Methods for integrated environmental assessment: research directions for the European Union, Stockholm Environment Institute, Stockholm, 1996.

Behrendt, H., Huber, P., Kornmilch, M., Opitz, D., Schmoll, O., Scholz, G., and Uebe, R.: Nutrient emissions into river basins of Germany, UBA-Texte 23/00, 1-288, Umweltbundesamt Berlin, Berlin, 2000.

Bennet, E. M., Carpenter, S. R., and Caraco, N. F.: Phosphorus and eutrophication: a global perspective, BioScience, 51(3), 227234, 2001.

Berkhout, F., Hertin, J., and Jordan, A.: Socio-economic futures in climate change impact assessment: using scenarios as "learning machines", Global Environ. Change, 12(2), 83-95, 2002.

Berry, M. A. and Rondinelli, D. A.: Proactive corporate environmental management: a new industrial revolution, Academy of Management Executive, 12(2), 38-50, 1998.

Börjeson, L., Höjer, M., Dreborg, K-H., Ekvall, T., and Finnveden, G.: Scenario types and techniques: Towards a user's guide, Futures, 38, 723-739, 2006.

Brown Gaddis, E. J., Vladich, H., and Voinov, A.: Participatory modeling and the dilemna of diffuse nitrogen management in a residencial watershed, Environ. Modell. Softw., 22, 619-629, 2007.

Burt, G. and van der Heijden, K.: First steps: towards purposeful activities in scenario thinking and future studies, Futures, 35, 1011-1026, 2003.

Carter, T. R., La Rovere, E. L., Jones, R. N., Leemans, R., Mearns, L. O., Nakicenovic, N., Pittock, A. B., Semenov, S. M., and Skea, J.: Developing and applying scenarios in Climate Change 2001: impacts, adaptation, and vulnerability, edited by: McCarthy, J. J., Canziani, O. F., Leary, N. A., Dokken, D. J., and White, K. S., contribution of Working Group II to the Third Assessment Report of the Intergovernmental Panel on Climate Change, Cambridge University Press, Cambridge, United Kingdom and New York, New York, 145-90, also available online at http://www.grida.no/climate/ipcc_tar/wg2/122.htm(accessed October 2003), 2001.

Cole, J. J., Peierls, B. L., Caraco, N. F., and Pace, M. L.: Nitrogen loadings of rivers as a human-driven process, in: Humans as Components of Ecosystems: The Ecology of Subtle Human Effects and Populated Areas: edited by: McDonnell, M. J. and Picket, S. T. A., Springer-Verlag, NY, 141-157 1993.

Diputació de Barcelona (Servei de Medi Ambient), Prat, N., VilaEscalé, M., Jubany, J., Miralles, M., Ordeix, M.: Qualitat ecològica del Llobregat, el Besòs, el Foix, la Tordera i el Ter: Informe 2003, Published by the Diputació de Barcelona, Institut d'Edicions, Barcelona, ISBN No. 84-9803-070-6, 2005.

EEA (European Environmental Agency): Participatory integrated assessment methods: an assessment of their usefulness for the European Environmental Agency, Technical Report 64, Copenhagen, 2001.

Galt, M., Tait, D., and Chicoine-Piper, M.: IDON Scenario Thinking: How to navigate the uncertainties of unknown futures, IDON, 1997.

Hisschemöller, M., Tol, R. S. J., and Vellinga, P.: The relevance of participatory approaches in integrated environmental assessment, Integrated Assessment, 2, 57-72, 2001.

Hofmann, J., Behrendt, H., Gilbert, A., Janssen, R., Kannen, A., Kappenberg, J., Lenhart, H., Lise, W., Nunneri, C., and Windhorst, W.: Catchment-coastal zone interaction based upon scenario and model analysis: Elbe and the German Bight case study, Reg. Environ. Change, 5, 54-81, 2005.

Jacquemin, A. and Wright, D.: The European challenges post1992: shaping factors, shaping actors, The Economic Journal, 104(424), 678-680, 1994.

Janssen, W. and Goldworthy, P.: Multidisciplinary research for natural resource management: conceptual and practical implications, Agricultural Systems, 51, 259-279, 1996.

Jöborn, A., Danielsson, I., Arheimer, B., Jonsson, A., Larsson, M. H., Lundqvist, L. J., Löwgren, M., and Tonderski, K.: Integrated water management for eutrophication control: public participation, pricing policy, and catchment modelling, Ambio: A Journal of the Human Environment, 34(7), 482-488, 2005.

Joss, S.: Toward the public sphere: Reflections on the development of participatory technology assessment, Bulletin of Science, Technology Society, 22(3), 220-231, 2002.

Kahn, H. and Wiener, A. J.: The year 2000: a framework for speculation on the next thirty-three years, Macmillan, New York, New York, USA, 1967.

Kok, K., Patel, M., Rothman, D. S., and Quaranta, G.: Multi-scale 
narratives from an IA perspective: Part II, Participatory local scenario development, Futures, 38, 285-311, 2006.

Ledoux, L., Beaumont, N., Cave, R., and Turner, R. K.: Scenarios for integrated river catchment and coastal zone management, Reg. Environ. Change, 5, 82-96, 2005.

Leeuwis, C.: Reconceptualizing participation for sustainable rural development: towards a negotiation approach, Dev. Change, 31, 931-959, 2000.

Leeuwis, C.: The stimulation of development and innovation: reflections on projects, planning, participation and platforms, European Journal of Agricultural Education and Extension, 2(3), 15-27, 1995.

Mercer, D.: Scenarios made easy, Long Range Planning, 28(4), 8186, 1995.

Middelkoop, H., Rotmans, J., van Asselt, M. B. A., Kwadijk, J. C. J., and van Deursen, W. P. A.: Development of perspective based scenarios for global change assessment for water management in the lower Rhine delta, UNESCO-WOTRO International Working Conference, "Water for Society", IHE Delft, 2000.

Mumford, E.: Advice for an action researcher, Information Technology \& People, 14(1), 12-27, 2001.

Nakicenovic, N., Alcamo, J., Davis, G., et al.: Intergovernmental Panel on Climate Change (IPCC) special report on emission scenarios (SRES), 2000.

Novotny, V.: Water Quality, 2nd ed., John Wiley \& Sons, New York, 2003.

Özkaynak, B.: Indicators and scenarios for urban development and sustainability, $\mathrm{PhD}$ Thesis, Autonomous University of Barcelona, 2005.

Parker, P., Letcher, R., Jakeman, A., Beck, M. B., Harris, G., Argent, R. M., Hare, M., Pahl-Wostl, C., Voinov, A., Janssen, M., Sullivan, P., Scoccimarro, M., Friend, A., Sonnenshein, M., Barker, D., Matejicek, L., Odulaja, D., Deadman, P., Lim, K., Larocque, G., Tarikhi, P., Fletcher, C., Put, A., Maxwell, T., Charles, A., Breeze, H., Nakatani, N., Mudgal, S., Naito, W., Osidele, O., Eriksson, I., Kautsky, U., Kautsky, E., Naeslund, B., Kumblad, L., Park, R., Maltagliati, S., Girardin, P., Rizzoli, A., Mauriello, D., Hoch, R., Pelletier, D., Reilly, J., Olafsdottir, R., and Bin, S.: Progress in integrated assessment and modelling, Environ. Modell. Softw., 17, 209-217, 2002.

Parry, M. and Carter, T.: Climate Impact and Adaptation Assessment, Earthscan Publications Ltd., London, UK, 1998.

Postma, T. J. B. M. and Liebl, F.: How to improve scenario analysis as a strategic management tool?, Technol. Forecast. Soc., 72, 161-173, 2005.

Raskin, P., Gallopin, G., Gutman, P., Hammond, A., and Swart, R.: Bending the curve: toward global sustainability, PoleStar Report Number 8, Stockholm Environment Institute, Stockholm, Sweden, 1998.

Ridder, D. and Pahl-Wostl, C.: Participatory integrated assessment in local level planning, Regional Environmental Change, 5, 188196, 2005.

Riera, J. L., Behrendt, H., Comas, J., Poch, M., Sabater, F., and Venohr, M.: Linking a catchment nutrient emission model (MONERIS) to a GIS and an Expert System for the management of Mediterranean streams: the European project STREAMES, Journal of Conference Abstracts on BIOGEOMON 2002, 4th International Symposium on Ecosystem Behaviour, 99, ISBN 07049-1023-3, 2002.
Rodríguez-Labajos, B.: Interlinked biological invasions in the Ebro river: a multi-scale scenario approach, Master dissertation, Autonomous University of Barcelona, Bellaterra, Spain, available online at http://selene.uab.es/brodriguezl, 2006.

Rotmans, J., van Asselt, M. B. A., de Bruin, A. J., den Elzen, M. G. J., de Freef, J., Hilderink, H., Hoekstra, A. Y., Hanssen, M. A., Köster, H. W., Martens, W. J. M., Niessen, L. W., and de Vries, H. J. M.: Global change and sustainable development: A modelling perspective for the next decade, RIVM report 461502004, Bilthoven, The Netherlands, 1996.

Rotmans, J. and Dowlatabadi, H.: Integrated assessment of climate change: Evaluation of methods and strategies, in: Human Choices and Climate Change: A State of the Art Report, Batelle Pacific Northwest Laboratories, Washington, DC, 1997.

Rotmans, J., van Asselt, M., Anastasi, C., Greeuw, S. C. H., Mellors, J., Peters, S., Rothman, D. S., and Rijkens, N.: Visions for a sustainable Europe, Futures, 32, 809-831, 2000.

Smeets, E. and Wetering, R.: Environmental Indicators, Typology and Overview, Technical Report No. 25, European Environment Agency, Copenhagen, 1999.

Tàbara, D. and Saurí, D.: The Muga river basin case study, Catalonia, Spain: case study report, HarmoniCop project report, available online at http://www.harmonicop.info, 2004.

Toth, F. L. and Hizsnyik, E.: Integrated environmental assessment methods: evolution and applications, Environ. Model. Assess., 3, 193-207, 1998.

Van der Heijden, K.: Scenarios: the Art of Strategic Conversation, Wiley, Chichester, UK, 1996.

Van Notten, P. W. F., Rotmans, J., van Asselt, M. B. A., and Rothman, D. S.: An updated scenario typology, Futures, 35, 423-443, 2003.

Vitousek, P. M., Aber, J., Howarth, R. W., Likens, G. E., Matson, P. A., Schindler, D. W., Schlesinger, W. H., and Tilman, G. D.: Human alteration of the global nitrogen cycle: causes and consequences, Ecol. Appl., 7, 737-750, 1997.

Wade, A. J.: Monitoring and modelling the impacts of global change on European freshwater ecosystems - introduction, Sci Total Environ., 365(1-3), 3-14, 2006.

WFD CIS Guidance Document No. 3: Analysis of Pressures and Impacts, Published by the Directorate General Environment of the European Commission, Brussels, ISBN 92-894-5123-8, ISSN 1725-1087, Dec 2002a.

WFD CIS Guidance Document No. 8: Public Participation in Relation to the Water Framework Directive, Published by the Directorate General Environment of the European Commission, Brussels, ISBN 92-894-5128-9, ISSN 1725-1087, Dec 2002b.

Wollenberg, E., Edmunds, D., and Buck, L.: Using scenarios to make decisions about the future: anticipatory learning for the adaptive co-management of community forests, Landscape Urban Plan., 65-77, 2000. 